\title{
Interlaminar shear strength study on CFRP/Al hybrid laminates with different properties
}

\author{
Costanzo Bellini, Vittorio Di Cocco, Luca Sorrentino \\ Department of Civil and Mechanical Engineering, University of Cassino and Southern Lazio, 03043 Cassino, Italy \\ costanzo.bellini@unicas.it, bttp://orcid.org/0000-0003-4804-6588 \\ vittorio.dicocco@unicas.it, bttp://orcid.org/0000-0002-1668-3729 \\ luca.sorrentino@unicas.it, bttp://orcid.org/0000-0002-5278-7357
}

\begin{abstract}
FML (Fibre Metal Laminate) is a hybrid material that presents outstanding structural properties, such as resistance to cyclic and dynamic loads, together with low specific weight. This material consists of metal sheets alternating to composite material layers. In the present work, the ILSS (Interlaminar Shear Strength) was evaluated for different types of carbon fibre/aluminium FML, produced varying the layer thickness and the bonding solution of layers. In fact, FMLs consisting of one or two metal sheets (a parameter strictly connected to the layer thickness, as the metal/composite volume fraction was kept at constant value) and bonded with structural adhesive or prepreg resin were considered for this study. The ILSS was determined according to the three-point bending method with short beam specimens. The experimental tests evidenced an effect of the adhesion methodology on the ILSS value, while the layer thickness did not influence the interlaminar strength. The mechanical behaviour after the maximum load point was investigated too, evaluating the trend of the shear stress as a function of the loading nose displacement.
\end{abstract}

KEYWORDS. CARALL; Short beam flexural test; Bonding strength.

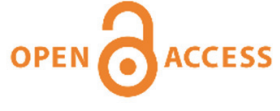

Citation: Bellini, C., Di Cocco, V., Sorrentino, L., Interlaminar shear strength variation of CFRP/Al hybrid laminates with different properties, Frattura ed Integrità Strutturale, 51 (2020) 442-448.

Received: 17.10 .2018

Accepted: 03.12.2019

Published: 01.01 .2020

Copyright: (C) 2020 This is an open access article under the terms of the CC-BY 4.0, which permits unrestricted use, distribution, and reproduction in any medium, provided the original author and source are credited.

\section{INTRODUCTION}

$\mathrm{F}$ ML is a particular hybrid material constituted by metal sheets alternated to composite material laminates. The mechanical properties of this material are very interesting, since it combines the high strength/weight ratio of composite materials with the ductility of metals [1]. One of the most widespread FML is the GLARE (Glass Laminate Aluminium Reinforced Epoxy), that consists in aeronautical grade aluminium sheets joined with glass fibre laminates. However, this kind of FML does not possess high stiffness, so in the past other types of FML have been investigated [2,3]. In particular, carbon fibre composites were considered for this application, giving rise to CARALLs (Carbon Fibre Reinforced Aluminium Laminates), that have higher stiffness, but they also are troubled with galvanic 
corrosion [4]. Indeed, the composite material nature strongly determines the structural characteristics of the whole hybrid laminate; in fact, a higher impact toughness is given by the aramid fibres, while carbon fibres are not suitable for this purpose; furthermore, the latter is more appropriate for high-cycle fatigue applications, while the former for low-cycle fatigue ones $[5]$.

In the present work, the influence of both the metal/composite bonding and the layer thickness on the ILSS value of different hybrid laminates was investigated. This kind of mechanical test was chosen because it highlights the characteristics of the interface between the constituents of the FML. In a composite material, the ILSS is a property that depends on the matrix, since it relies on the adhesion between matrix and fibres. In an FML, the adhesion between metal sheets and composite material layer holds the same role; in fact, the rupture generally happens at the interface between these materials. The surface preparation is a factor that must be evaluated when designing FMLs and composites in general for critical applications [6].

The ILSS of a laminate is an important parameter since the separation of the layers, that is the delamination, makes the bending stiffness drop and, consequently, the bending deformation grow. It is important to emphasize that the attention was paid not only to the maximum reached loads but also to the whole force-displacement curves, in order to evaluate the behaviour prior to and after the main damage occurrence. Other significant singularities of the present work consist in the reinforcement architecture and the stacking sequence: other researchers considered unidirectional reinforcements and metal sheet as external layers, while this work deals with woven fabric and the external layers are made of composite material. In the literature there are some other works dealing with the ILSS of FMLs, but, to our best knowledge, the analysis of the effect of both the layer thickness and the metal/composite interface on the ILSS and the loading curves has never been investigated. Several works aimed at improving the bonding between metal and composite material. Three different solutions for CARALL were compared by Ning et al.: the enhancement of the composite-metal interface due to the addition of nanoparticles and the chemical etching or mechanical patterning on the surface of the metal sheet. The influence of the surface treatment of the sheet for the production of GLARE was investigated by Mamalis et al. [7] and Park et al. [8]. The advisability of a glass layer at the metal/composite interface of a CARALL was evaluated by Jakubczak et al. [9]. The influence of the fibre treatment on the mechanical characteristics was compared for a composite laminate and a FML by Lawcock et al. [10,11]. The effects of adhesive thickness between metal and composite on the structural characteristics of GLARE was investigated by Li et al. [12]; instead, the influence of loading conditions on the shear strength and the damage mechanism were studied by Liu et al. [13]. The influence of the hygrothermal ageing on the ILSS of CARALL was investigated by Botelho et al. [14] and by Pan et al. [15], while that of testing temperature on the ILSS of GLARE was studied by Hinz et al. [16]. An in-depth study on the flexural behaviour of different types of CARALL, characterized by different layer thickness and composite/metal bonding, was carried out by Bellini et al. [17-20].

\section{MATERIALS AND METHODS}

A $\mathrm{s}$ mentioned in the introduction paragraph, in this work the shear strength of CFRP/Al hybrid laminates was examined. In particular, the aim consisted in assessing the influence of the layer thickness and the interface bonding on the ILSS of this type of material. An experimental plan was conceived, that considered two levels for each explored factor; therefore, a total of three different laminates were produced. As concerns the layer thickness, a type of laminate presented three CFRP layers and two aluminium sheets, while the other was constituted by two aluminium sheets and a CFRP layer. It must be remembered that all the laminates presented the composite material as external layers, while the metal was inside. Moreover, the thickness of the various layers was chosen in order to obtain a constant composite material/metal ratio and a total laminate thickness equal to $5 \mathrm{~mm}$. Consequently, the metal sheet thickness was $0.3 \mathrm{~mm}$ or $0.6 \mathrm{~mm}$ (for the FML with two sheets or a single sheet, respectively) and the number of prepreg plies was 12, that were grouped in threes or fours to produce both types of FML. As regards the other parameter, that is the bonding solution between aluminium and CFRP, a kind of laminates was produced inserting a layer of structural adhesive, the AF $1622 \mathrm{k}$, at the interface, while in the other one any adhesive was absent, hence the adhesion relied on the prepreg resin only.

All the FML analysed in this work were manufactured considering the prepreg hand layup process, also known as vacuum bag process, a manufacturing technique common in the aeronautical industry. Several steps were necessary to make the laminates. The process started with the mould preparation: a release agent was spread on the surface of a steel plate, that had a thickness of $10 \mathrm{~mm}$, in order to allow part removal at the end of the curing process. After, the prepreg plies and the metal sheets were cut in the suitable dimensions and stacked on the mould, paying attention to respect the established stacking sequence. Then, the vacuum bag was prepared using all the necessary ancillary materials, as the release film and the breather fabric, and the laminates were sealed under the vacuum bag. Once the sealing operation was concluded, the mould 
with the prepreg was inserted in the autoclave for curing. Six specimens were extracted from each laminate by diamond disk saw cutting, then they were tested according to ASTM D 2344. In Fig. 1 a type of specimen, that one with one metal sheet, is visible. This test method calculated the ILSS of laminate through the three-point bending of a short beam, that is a bending test with a span-to-thickness ratio of four. Considering that the laminate thickness was $5 \mathrm{~mm}$, the span was set to $20 \mathrm{~mm}$, so the length of the specimens was decided to be $25 \mathrm{~mm}$, while the width was $10 \mathrm{~mm}$. The ASTM standard prescribed also a fixed load speed of $1 \mathrm{~mm} / \mathrm{min}$.

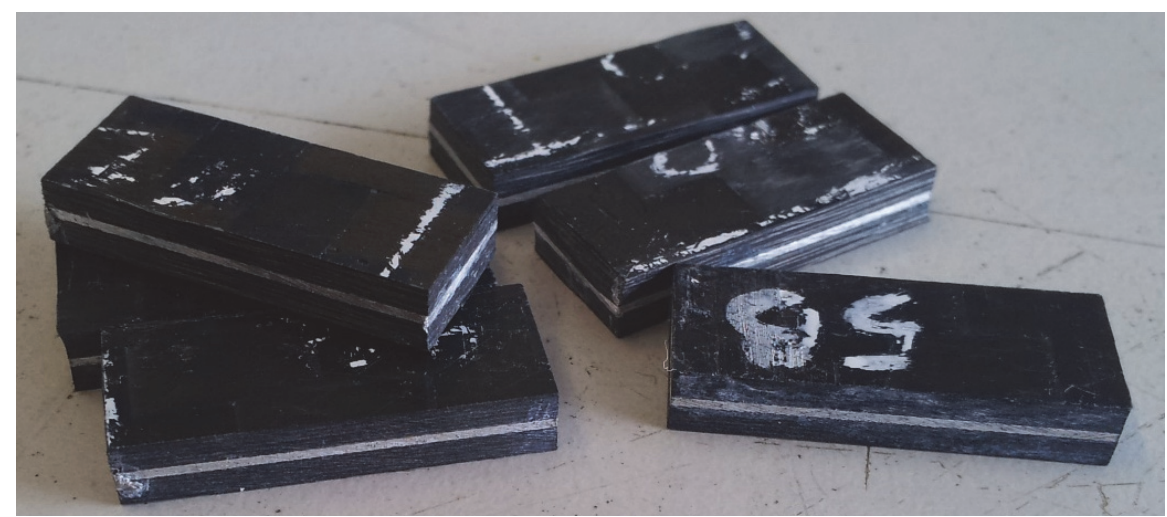

Figure 1: Short beam specimens with a single aluminium sheet.

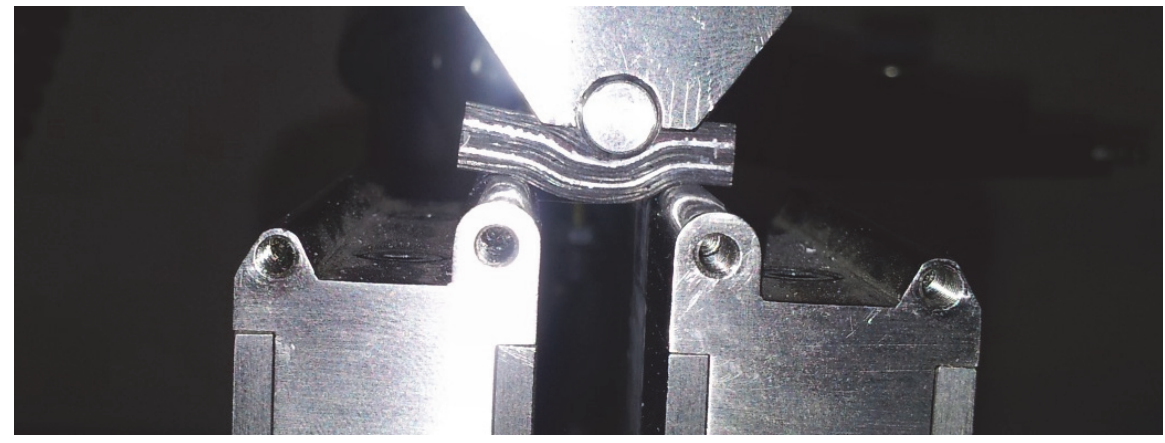

Figure 2: A specimen during the three-point bending test.

\section{RESULTS}

he results of the experimental tests carried out on short beam specimens are presented in this section. Both the maximum ILSS and the trend of the shear strength were reported and discussed. In particular, a statistical analysis was carried out on the values found for the ILSS in order to establish if the layers thickness and the metal/composite interface affected this structural parameter. Considering a specimen width b and a specimen thickness h, the ILSS due to the load P can be determined through the following relation, as stated in the ASTM D 2344 standard:

$$
\operatorname{ILSS}=\frac{3 P}{4 b b}
$$

The ILSS values obtained from the three-point bending tests carried out on all the specimens produced in this activity are presented in Fig. 3. It can be noted that the highest shear strength was equal to $49.03 \mathrm{MPa}$ and it was reached by the laminate characterised by a single metal sheet and metal/composite bonding assured by structural adhesive, while the lowest value was equal to $39.08 \mathrm{MPa}$ and was obtained by the other laminate with a singular metal sheet, that one without structural adhesive. Considering the average value, this finding was confirmed, in fact the highest strength belonged to the laminate with a single metal sheet bonded with adhesive and the lowest strength to the one bonded with the prepreg resin, while the strength of the remaining laminate reached a value between the former two. Moreover, the experimental values are quite accurate since the $\mathrm{CoV}$ (Coefficient of Variation) of the results is low, in fact it ranged between $3.6 \%$ and $3.7 \%$ for all the 
tests. The presence of the adhesive improved the ILSS of the material, but it must be remembered that it was detrimental for the flexural strength of the laminate, as found in previous works $[17,20]$.

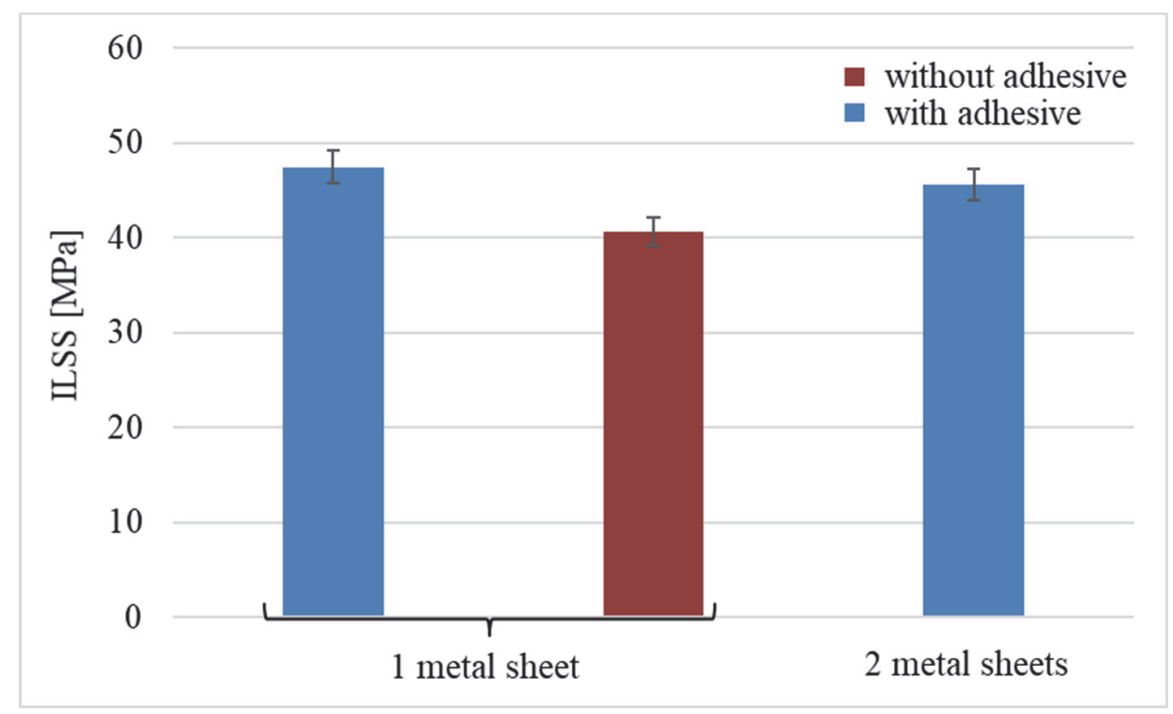

Figure 3: Results relevant to the three-point bending tests carried out on the produced FML.

The consistency of the data obtained from the experimental tests was assessed by statistical analysis; in particular, an ANOVA (Analysis of Variance) was carried out, and the results are reported in Tab. 1. This statistical tool asserted that the contribution factor of the layer thickness was quite low, less than $5 \%$, while the contribution of the interface solution was high, more than $75 \%$. The interaction contribution was calculated too, but the result was negligible and so it is not present in Tab. 1. In order to confirm these findings, the ANOVA was completed with the estimation of the p-value, another statistical parameter: the studied factor is not influencing the results if its p-value is higher than $5 \%$, that is the value commonly used as limit. As visible in the table, the adhesion factor had a p-value equal to $0 \%$, so it was influencing, while the number of sheets had a value of almost $13 \%$, so it was unaffecting. Therefore, it can be concluded that among the studied factor, the only one that conditioned the ILSS value was the presence of the structural adhesive at the interface between metal and composite material.

\begin{tabular}{ccc}
\hline Source & Contribution & p-value \\
$\begin{array}{c}\text { Number of } \\
\text { sheets }\end{array}$ & $4.85 \%$ & $12.9 \%$ \\
$\begin{array}{c}\text { Presence of } \\
\text { adhesive }\end{array}$ & $75.84 \%$ & $0.0 \%$ \\
$\begin{array}{c}\text { Experimental } \\
\text { error }\end{array}$ & $19.31 \%$ & \\
Total & $100 \%$ & \\
\hline
\end{tabular}

Table 1: ILSS value measured for all the tested specimen.

The factor influence on the short beam strength was investigated also through the main effects plot, another statistical instrument, and the results of this analysis are presented in Fig. 4. As it can be seen from the chart in the figure, the ILSS increased with the adhesive presence, while it decreased with the increment of the number of sheets, even if this decrement was lower compared to the variation induced by the former factor, as stated also by the ANOVA.

The trend of the shear strength as a function of the loading nose displacement is presented in Fig. 5. For each kind of laminate, a single curve is reported, that is representative of the relevant group because the data scatter was narrow. The shear stress trend was found comparable for all the specimen type; in fact, at first a shear stress increment was found, then, after the attainment of maximum load, each curve showed a fluctuating trend, due to the presence of various failures. The first part of the curve, till the maximum load, showed a linear trend for the laminate without the adhesive, while the other two types presented a slight knee before attaining the maximum value. This behaviour was probably caused by the plasticization of the adhesive layer, that in the former kind of laminate was not present. The slope of the first part of the 
curves, that is faintly connected to the stiffness of the laminate, was steeper for the laminate without the adhesive. This finding is due to the lower stiffness of the adhesive, that conditioned the behaviour of the whole laminate, and it confirmed what found in a previous work [20]. The laminates with a single aluminium sheet presented a steep stress decrease after the maximum value, that was equal to $36 \%$ for the FML bonded with the prepreg resin and $22 \%$ for the laminate bonded with the structural adhesive, while for the laminate with two metal sheet the shear decrease was more gradual. The laminate without the adhesive presented also a load recovery, while this load increment was negligible for the other laminates; in fact, the shear stress level after the first drop increased till a value equal to $82 \%$ of the maximum load. Finally, it must be noted that all the laminates presented a residual load capacity; in particular, the laminate with two metal sheets presented the highest value, that was equal to $64 \%$ of the maximum load, while it was $46 \%$ for the laminate with a single sheet bonded with prepreg resin and $41 \%$ for that one bonded with adhesive. In conclusion, it can be stated that the best choice was the laminate with two aluminium sheets bonded with the adhesive, since it presented a maximum ILSS slightly lower than the highest one, that was relevant to the other laminate bonded with adhesive, the highest residual load capacity and after the attainment of the maximum ILSS the shear stress trend did not show a drop.

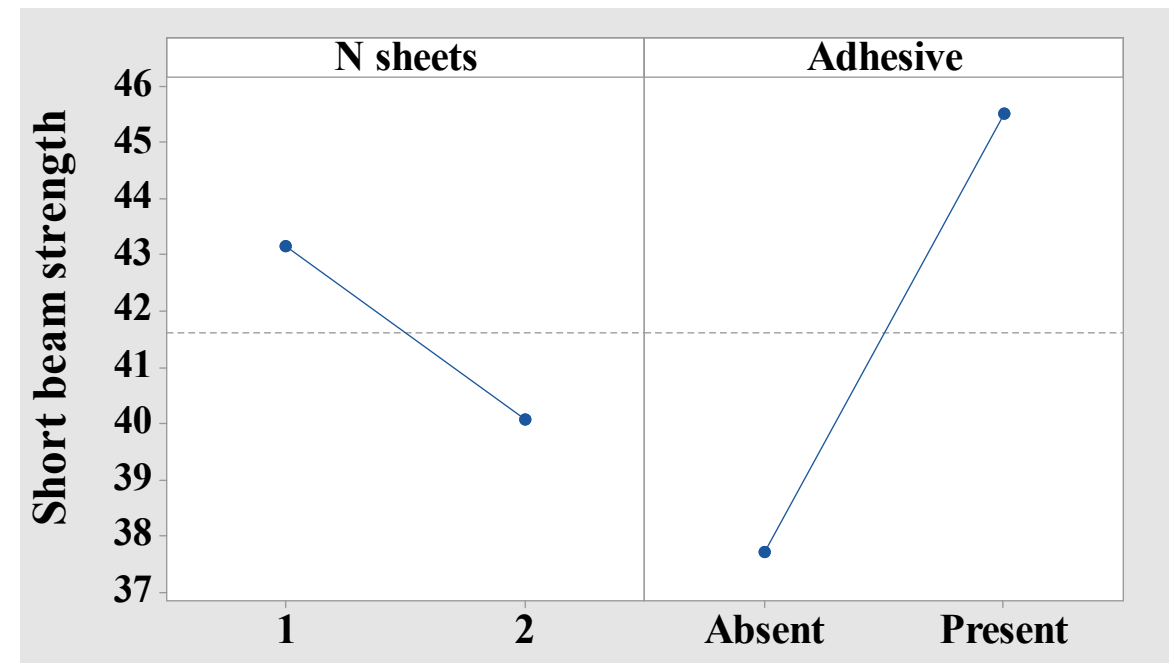

Figure 4: Main effect plot relevant to experimental tests.

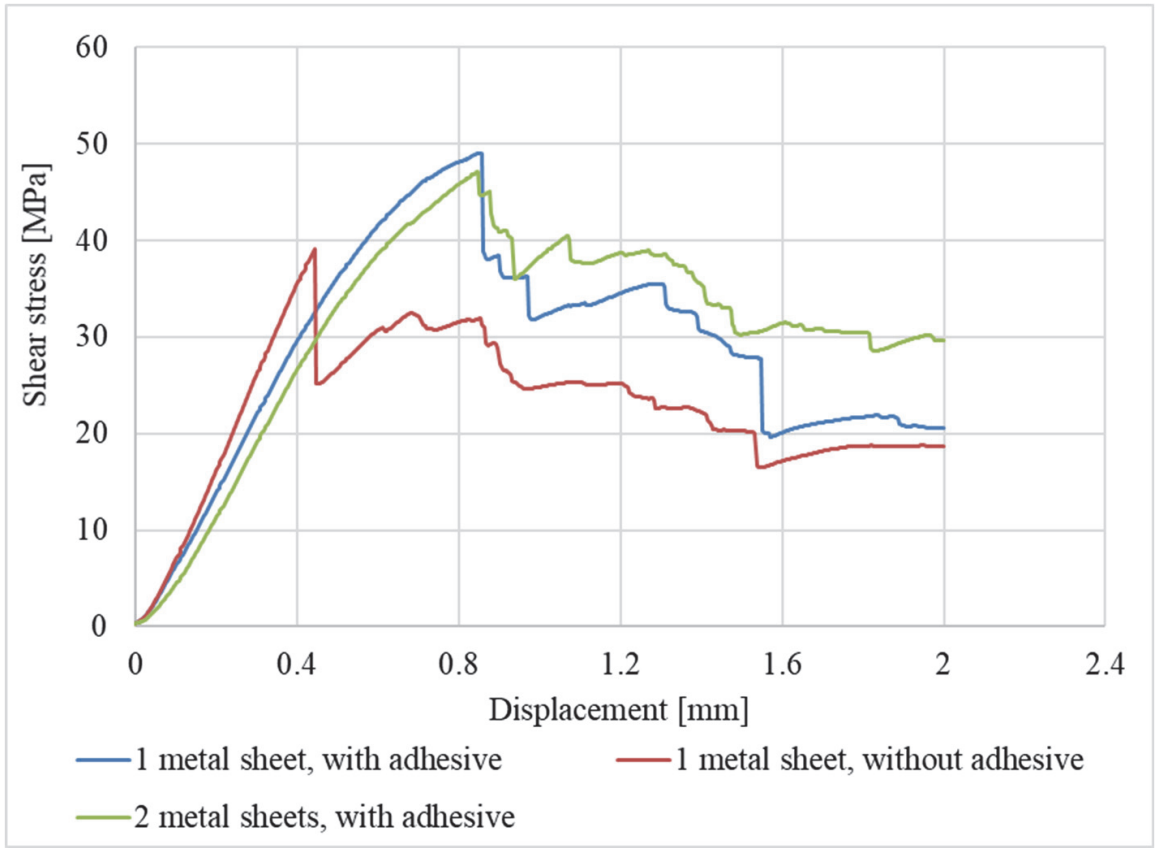

Figure 5: Shear stress as a function of displacement for the tested specimens. 


\section{CONCLUSIONS}

$\mathrm{F}$

LMs are hybrid laminates, constituted by metal sheets and composite material layers interposed, that present high structural properties. However, the reliability of the interface between metal and composite is very important; for this reason, the influence of the metal/composite interface and the stacking sequence on the ILSS (interlaminar shear strength) was investigated in the present work. In particular, for the first factor the bonding agent consisted in a structural adhesive or the resin of the prepreg itself, while, for the second factor, the number of metal sheets was varied: a single sheet or two ones were considered, maintaining at a constant value the volume ratio between carbon fibre and aluminium, in order to obtain different layer thickness. The ILSS was chosen as parameter to be studied since it relied on the interface effectiveness, and it was determined through the three-point bending test on short beam.

Three types of specimens were produced and tested: the first one with a single metal sheet bonded with adhesive, the second one with a single metal sheet bonded with prepreg resin and the third one with two aluminium sheets bonded with adhesive. The experimental tests found that the laminate showing the highest ILSS was the first one, while the second one presented the lowest value. Moreover, a statistical analysis was performed on the experimental results for stating the influence level of the different factors, and it was discovered that the layer thickness had a low effect on the shear strength, while the interface typology was the most influencing factor.

The work was completed with the analysis of the shear stress trend as a function of the loading nose displacement. All the specimens showed a linear (or almost linear) shear stress increase till a maximum value, followed by a sharp drop, except for the laminate with two aluminium sheets that presented a smoother load decrease. The same laminate was characterized also by the highest residual load at the end of the experimental test.

\section{REFERENCES}

[1] Fu, Y., Zhong, J., Chen, Y. (2014). Thermal postbuckling analysis of fiber-metal laminated plates including interfacial damage, Compos. Part B Eng., 56, pp. 358-364, DOI: 10.1016/j.compositesb.2013.08.033.

[2] Lee, B.E., Park, E.T., Kim, J., Kang, B.S., Song, W.J. (2014). Analytical evaluation on uniaxial tensile deformation behavior of fiber metal laminate based on SRPP and its experimental confirmation, Compos. Part B Eng., 67, pp. 154 159, DOI: 10.1016/j.compositesb.2014.06.031.

[3] Li, H., Hu, Y., Xu, Y., Zheng, X., Liu, H., Tao, J. (2015). Reinforcement effects of aluminumelithium alloy on the mechanical properties of novel fiber metal laminate, Compos. Part B Eng., 82, pp. 72-77, DOI: 10.1016/j.compositesb.2015.08.013.

[4] Hamill, L., Hofmann, D.C., Nutt, S. (2018). Galvanic Corrosion and Mechanical Behavior of Fiber Metal Laminates of Metallic Glass and Carbon Fiber Composites, Adv. Eng. Mater., 20(2), pp. 1-8, DOI: 10.1002/adem.201700711.

[5] Botelho, E.C., Silva, R.A., Pardini, L.C., Rezende, M.C. (2004). Evaluation of adhesion of continuous fiber-epoxy composite/aluminum laminates, J. Adhes. Sci. Technol., 18(15-16), pp. 1799-1813, DOI: 10.1163/1568561042708377.

[6] Sorrentino, L., Polini, W., Bellini, C., Parodo, G. (2018). Surface treatment of CFRP: influence on single lap joint performances, Int. J. Adhes. Adhes., 85, pp. 225-233, DOI: 10.1016/j.ijadhadh.2018.06.008.

[7] Mamalis, D., Obande, W., Koutsos, V., Blackford, J.R., Ó Brádaigh, C.M., Ray, D. (2019). Novel thermoplastic fibremetal laminates manufactured by vacuum resin infusion: The effect of surface treatments on interfacial bonding, Mater. Des., 162, pp. 331-344, DOI: 10.1016/j.matdes.2018.11.048.

[8] Park, S.Y., Choi, W.J., Choi, H.S., Kwon, H. (2010). Effects of surface pre-treatment and void content on GLARE laminate process characteristics, J. Mater. Process. Technol., 210(8), pp. 1008-1016, DOI: $10.1016 /$ j.jmatprotec.2010.01.017.

[9] Jakubczak, P., Bienias, J., Surowska, B. (2018). Interlaminar shear strength of fibre metal laminates after thermal cycles, Compos. Struct., 206, pp. 876-887, DOI: 10.1016/j.compstruct.2018.09.001.

[10] Ye, L., Afaghi-Khatibi, A., Lawcock, G., Mai, Y.W. (1998). Effect of fibre/matrix adhesion on residual strength of notched composite laminates, Compos. Part A Appl. Sci. Manuf., 29(12), pp. 1525-1533, DOI: $10.1016 /$ S1359-835X(98)00071-2.

[11] Lawcock, G., Ye, L. (1998). Effects of Fibre / Matrix Adhesion on Carbon-Fibre- Reinforced Metal Laminates I. Residual Strength, Compos. Sci. Technol., 3538(97), pp. 1609-1619.

[12] Li, H., Hu, Y., Fu, X., Zheng, X., Liu, H., Tao, J. (2016). Effect of adhesive quantity on failure behavior and mechanical properties of fiber metal laminates based on the aluminum-lithium alloy, Compos. Struct., 152, pp. 687-692, DOI: 10.1016/j.compstruct.2016.05.098. 
[13] Liu, C., Du, D., Li, H., Hu, Y., Xu, Y., Tian, J., Tao, G., Tao, J. (2016). Interlaminar failure behavior of GLARE laminates under short-beam three-point-bending load, Compos. Part B Eng., 97, pp. 361-367,

[14] DOI: 10.1016/j.compositesb.2016.05.003.

[15] Botelho, E.C., Pardini, L.C., Rezende, M.C. (2007). Evaluation of hygrothermal effects on the shear properties of Carall composites, Mater. Sci. Eng. A, 452-453, pp. 292-301, DOI: 10.1016/j.msea.2006.10.127.

[16] Pan, L., Ali, A., Wang, Y., Zheng, Z., Lv, Y. (2017). Characterization of effects of heat treated anodized film on the properties of hygrothermally aged AA5083-based fiber-metal laminates, Compos. Struct., 167, pp. 112-122, DOI: $10.1016 /$ j.compstruct.2017.01.066.

[17] Hinz, S., Heidemann, J., Schulte, K. (2005). Damage evaluation of GLARE 4B under interlaminar shear loading at different temperature conditions, Adv. Compos. Lett., 14(2), pp. 47-55.

[18] Bellini, C., Di Cocco, V., Iacoviello, F., Sorrentino, L. (2019). Performance evaluation of CFRP/Al fibre metal laminates with different structural characteristics, Compos. Struct., 225, pp. 111117, DOI: 10.1016/j.compstruct.2019.111117.

[19] Bellini, C., Di Cocco, V., Iacoviello, F., Sorrentino, L. (2019). Flexural strength of aluminium carbon/epoxy fibre metal laminates, Mater. Des. Process. Commun., 1, pp. e40, DOI: 10.1002/mdp2.40.

[20] Bellini, C., Cocco, V. Di., Iacoviello, F., Sorrentino, L. (2019). Influence of structural characteristics on the interlaminar shear strength of CFRP/Al fibre metal laminates, Procedia Struct. Integr., 18, pp. 373-378, DOI: $10.1016 /$ j.prostr.2019.08.177.

[21] Bellini, C., Di Cocco, V., Iacoviello, F., Sorrentino, L. (2019). Experimental analysis of aluminium carbon/epoxy hybrid laminates under flexural load, Frat. Ed Integrità Strutt., 49, pp. 739-747, DOI: 10.3221/IGF-ESIS.49.66. 